\title{
The comparative study on two kinds of speed governing schemes of spray-painting set hydraulic system
}

\author{
Jun $\mathrm{Du}^{1, \mathrm{a}^{,}, \text {} \text { Ping Zhang }}{ }^{1, \mathrm{~b}}$, Jun $\mathrm{Ji}^{1, \mathrm{c}}$ \\ ${ }^{1}$ Beijing Polytechnic, Beijing100176 China

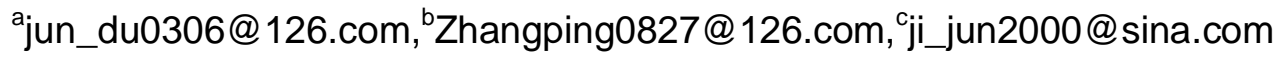

\begin{abstract}
Keywords: sparger device; throttling valve; compensated flow control valve; speed governing method; stability

Abstract:When paint-spraying a batch of small size parts in an assembly line, for some parts with different weights, the speed of sparger device transmission conveyor should keep unchanged in order to ensure the paint-spraying quality and effect. Through analysis and comparison to the structure of throttling valve, compensated flow control valve and some stability elements for speed governing, this paper discusses and optimizes speed governing methods of sparger device hydraulic control system.

The spray-painting set can be used to fulfill the spray-painting of small-sized component in assembly line production. Normally, a set of spray-painting equipment spray not only the same weight component and the weight of the sprayed component varies in some range. However, the band carrier of spray-painting set is required to remain its speed with stability to ensure the spraying quality. Therefore, the choice of different speed governing schemes for band carrier has a direct influence to the spraying quality and effect of components.
\end{abstract}

\section{Designing scheme of spray-painting set hydraulic system}

Designing scheme of spray-painting set hydraulic system shows as the following figure 1:

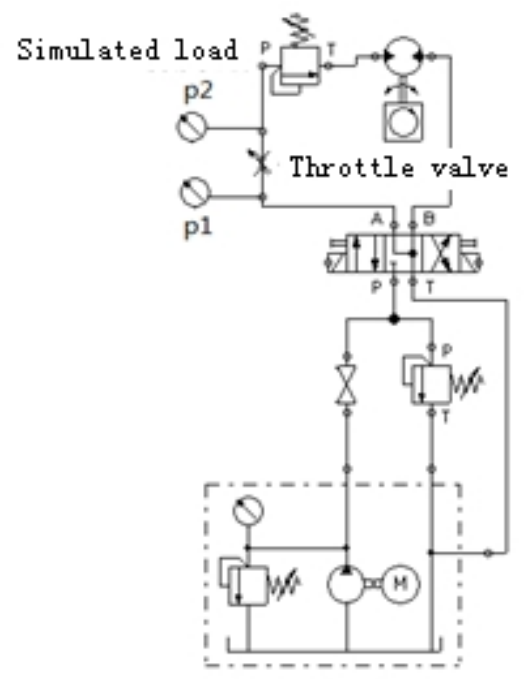

(a)

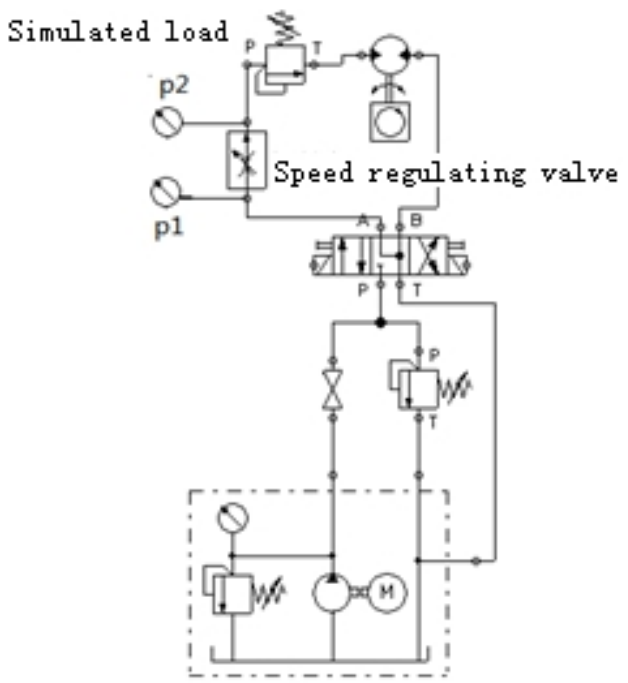

(b)

Figure 1: Comparison of designing scheme of spray-painting set hydraulic system

In the hydraulic speed governing system, proceeding from expected effect and requirements, taking the backward inference method, different speed governing components could be chosen for different stability effects as (a) and (b) shown in figure 1 in which adjustable throttling valve and 
speed governing valve are used respectively. The flood valve is adopted in the loop as artificial load (hereafter referred to as load)[1]. Two consequences of speed stability in executive station will appear according to the flux stability transported to the executive component from the system when the weight of the would-be painted component that is the load varies.

\section{The comparison analysis of structure principle between the adjustable throttling valve and speed governing one.}

For adjustable throttling valve and speed governing one, the speed governing is achieved via the control to flux Q which flows into the executive components. When the hydraulic system works, the vary feedback from the load will cause the change of differential pressure of front and back of the valve. This change will affect the fluxinput into the executive end and the speed stability of executive component.

The flux of adjustable throttling valve could be calculated with the following formula:

$Q=K \cdot A \cdot \Delta P^{m}$ ( formula 1)

$\mathrm{K}$ in formula 1 refers to the coefficient related to elements like shape of regulator orifice, liquid flux and nature of oil or liquid. A refers to the through-flux sectional area of the regulator orifice, $\Delta p$ stands for the differential pressure of front and back of the regulatororifice, and $\mathrm{m}$ is regulator orifice index related to the shape of the regulator orifice[2].

When the regulator orifice size is set and the throttling valve works, the flux is stable. In reality, the change of load can be directly reflected as throttling valve exit pressure and make the differential pressure $\Delta p$ change. It can be seen from formula (1) that the bigger $m$ is, the bigger effect $\Delta p$ has to flux. Reflected in the hydraulic speed governing system, the effect degree from both ends differential pressure to flux is the change scope of executive end speed. The following formula can explain it.

$$
v=\frac{Q}{A}
$$

As it is shown, under the circumstance of other things unchanged, the stability of the speed depends on the flux of throttle valve; the flux depends on the throttle valve structure and the size of opening degree in the hydraulic system. The common adjustable throttle valve port structures are as the following:

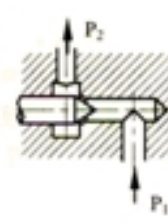

(a)

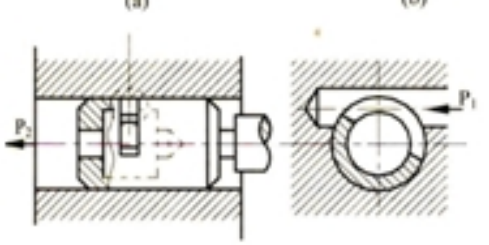

(d)
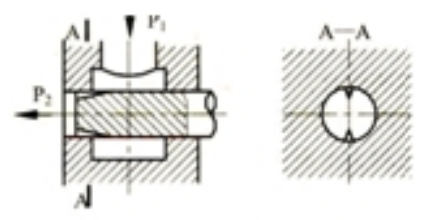

(c)

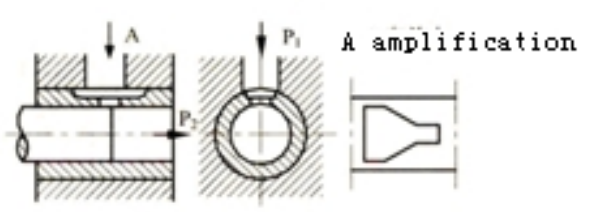

(e)

Figure 2: The regulator orifice structural style 
With the hydro-mechanical principle and experimental verification, we can see that whatever the regulator orifice structural style above is, it has a stability problem according to the change of load which moves in the hydraulic system. Take axial direction triangle slot regulator orifice in (c) above as an example, in this structure, one to three triangle grooves are made on the top of a cylinder valve element which can form a gradually varied orifice area groove together with the throttle valve body and enhance an axial movement to the valve element. Therefore, the sectional area flowed through triangle groove will be changed and the flux can be adjusted. In high-pressure valve, the triangle groove can be replaced by the slope to improve the technology. Along with the axial direction, the groove is in the same direction as flowing liquid to achieve a relative stable liquid flux state. Generally, the triangle grooves are $120^{\circ}$ or $180^{\circ}$ axis-centered symmetrically distributed to balance the radial force of valve element. As a result, the speed stability reflected to the execute end of the hydraulic system is relatively high when the system load changes (the differential pressure from either ends increases or decreases) [3].

As the following figure 3 shows, sparger device hydraulic system in above 1(a) use this kind valve port throttling valve:

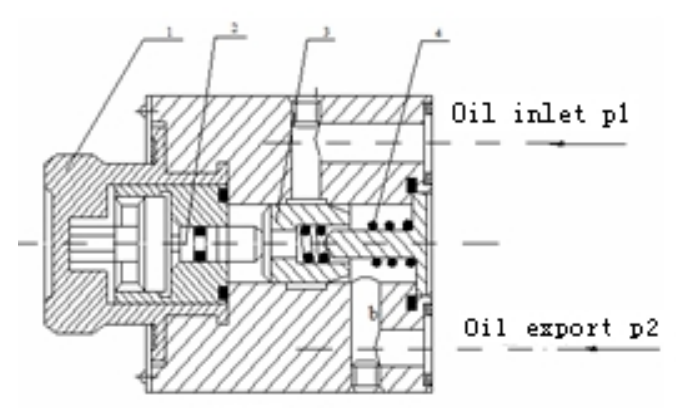

Figure 3: Throttling valve structure

1-Reguiator hand 2-Push rod 3-Valve core 4-Spring

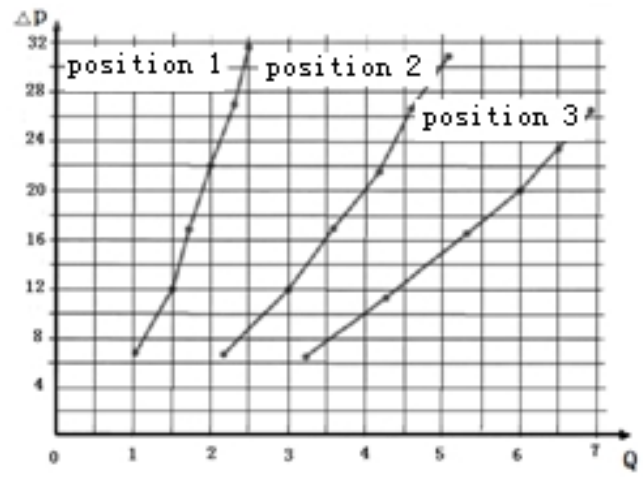

Figure4:Throttling valve $\Delta \mathrm{p}-\mathrm{Q}$ characteristic curve

The differential pressure $\Delta p$ varies according to the system external load. No. 1 in figure 3, the adjust handlebars, the positions are in every second round. When the opening degrees of regulator orifice are set in three different positions, the load flux features can be observed as the following table.

Table 1: Throttling valve measurement calculation

\begin{tabular}{|c|c|c|c|c|c|c|c|c|c|c|c|}
\hline \multicolumn{4}{|c|}{ position 1 } & \multicolumn{4}{|c|}{ position 2 } & \multicolumn{4}{|c|}{ position 3 } \\
\hline $\begin{array}{c}P_{2} \\
\text { bar }\end{array}$ & $P_{1}$ & $\Delta p$ & $Q$ & $P_{2}$ & $P_{1}$ & $\Delta p$ & $Q$ & $P_{2}$ & $P_{1}$ & $\Delta p$ & $Q$ \\
\hline 20 & 51.7 & 29.8 & 2.4 & 20 & 51.2 & 31 & 5.1 & 20 & 46.3 & 26.2 & 6.8 \\
\hline 25 & 52 & 27 & 2.3 & 25 & 51.4 & 26.5 & 4.6 & 25 & 48.5 & 23.4 & 6.5 \\
\hline 30 & 52 & 22 & 2 & 30 & 51.8 & 21.7 & 4.3 & 30 & 51 & 20 & 6.1 \\
\hline 35 & 52 & 17.2 & 1.6 & 35 & 52 & 17.2 & 3.6 & 35 & 51.3 & 16.2 & 5.3 \\
\hline 40 & 52 & 12.1 & 1.4 & 40 & 52 & 12 & 3.1 & 40 & 51.5 & 11.4 & 4.4 \\
\hline 45 & 52 & 7.2 & 1 & 45 & 52 & 7.2 & 2.3 & 45 & 51.8 & 6.7 & 3.2 \\
\hline
\end{tabular}

According to table 1 and the analysis of characteristic curve, the flux gets rapid with a big differential pressure; that is to say, the bigger the differential pressure gets, the larger the flux is, the 
worse the speed stability is in the hydraulic system. Under the circumstance of a set opening degree of regulator orifice, the flux has an obvious change according to the differential pressure. So, reflected in the 1(a) of sparger device, the speed of band carrier in the device will have an instable change with various weight of parts. The above elements will directly influence the paint spraying quality to the parts.

Speed governing valve is a kind of throttling valve which has pressure compensation, and it is in series with both uniform-pressure-drop valve and ordinary throttling valve. Its structure is as the following figure shows.

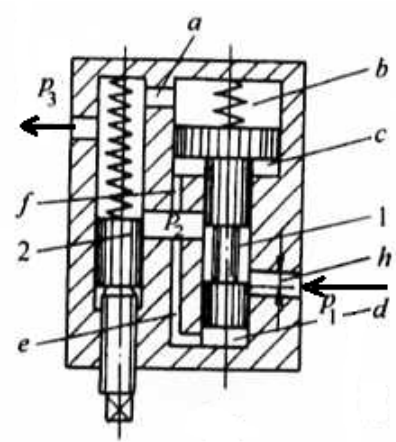

Figure 5: Structure of compensated flux control valve(1-Uniform-pressure-drop valve element 2-Throttling valve element)

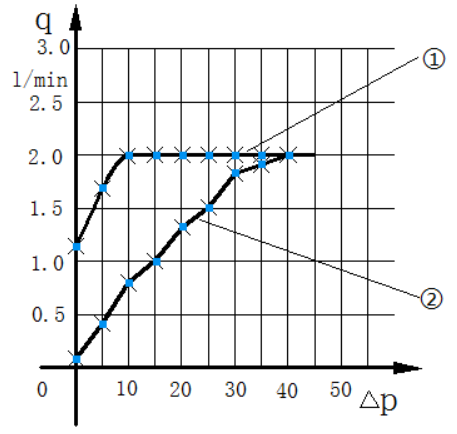

Figure 6: Spraying device load- flux feature (1)Compensated flow control valve load-flux feature

(2) Throttling valve load-flux feature)

When the oil of pressure $\mathrm{p} 1$ going through reducing valve $\mathrm{h}$, the oil pressure reduces to $\mathrm{p} 2$; through a, f, e, p2 and p3(the pressure before and after the throttling valve element) are respectively led to cavity b, c which are on the top of the uniform-pressure-drop valve element and $d$ which is at the bottom; through exit of compensated flow control valve, the other part oil of pressure p3 enters executive component; when compensated flow control valve working steadily, under the effect of b cavity spring force, oil pressure p3, p2 in c and d cavity( excluding flow force, friction force and gravity), the reducing valve element 1 is inan equilibrium position. When the load increasing, pressure p3 gets bigger and hydraulic pressure affected on b cavity on the top of reducing valve element 1 gets bigger as well; valve element gets down, relief port gets wider, pressure drop reduces, p2 gets larger, so the differential pressure (p2-p3) of throttling valve can keep unchanged; and vice versa. If the flux which goes through compensated flow control valve remains, the speed of executive end can maintain stable. Therefore, with the effect of uniform-pressure-drop valve self-compensation load change, there is a fixed value for the differential pressure before and after throttling valve and effect elimination to flux from load change[4].

\section{The feature comparison of load-flux between two kinds of speed governing method}

Choosing compensated flow control valve as shown in 1(b), setting the exit pressure of pump when working, when artificial load (the spray-painted parts) changing, the sparger device hydraulic system gets the following fluxdata of two methods. 
Table 2: Spraying device load- flux number

\begin{tabular}{|c|c|c|c|c|}
\hline $\begin{array}{l}\text { Entrance } \\
\text { pressure } \\
\text { p1 (bar) }\end{array}$ & $\begin{array}{l}\text { Exit } \\
\text { pressure } \\
\mathrm{p} 2 \text { (bar) }\end{array}$ & $\begin{array}{c}\text { Pressure } \\
\text { difference } \\
\Delta p \text { (load bar) }\end{array}$ & $\begin{array}{l}\text { Compensated flow } \\
\text { control valve flux } \\
\text { qt (1/min) }\end{array}$ & $\begin{array}{l}\text { Throttling valve } \\
\text { flux qj (1/min) }\end{array}$ \\
\hline 50 & 10 & 40 & 2 & 2 \\
\hline 50 & 15 & 35 & 2 & 1.9 \\
\hline 50 & 20 & 30 & 2 & 1.8 \\
\hline 50 & 25 & 25 & 2 & 1.3 \\
\hline 50 & 30 & 20 & 2 & 1.0 \\
\hline 50 & 35 & 15 & 2 & 0.7 \\
\hline 50 & 40 & 10 & 2 & 0.4 \\
\hline 50 & 45 & 5 & 1.7 & 0.1 \\
\hline 50 & 50 & 0 & 1.2 & 1 \\
\hline
\end{tabular}

According to data in table 2 and the analysis of curve in figure 6 , when the weight of spray-painted part (the load $\Delta p$ ) changes, the flux data changing law measured according to method (a) and (b) will obviously different. Curve (1) is the feature of compensated flow control valve load-flux, with the load change, so its stability will be excellent with aflux over 10bar; curve (2) is the feature of throttling valve load-flux, with the load change, so its flux will see a changing and increasing momentum. This comparison is consistent with the above theory contrastive analysis between adjustable throttling valve and compensated flow control valve.

\section{Conclusion}

The load change can lead the change of system pressure and reflect the flux variety and in the end affect the stability of executive end. The throttling valve load change in method (a) directly reflects the speed instability; the compensated flow control valve in method (b) can make pressure compensation and provide relatively constant flux, which guaranty speed stability of executive end. This is a crucial link in sparger device to make sure the paint spraying quality.

\section{References:}

[1]JiaXinming, Hydraulic drive and control,thirded.,National DefenseIndustryPress,Beijing, 2001. pp.133-140

[2]Shi Xinian, Hydraulic transmission,scendeded.China University of Mining andTechnology Press, Beijing,1990.pp.45-56

[3]Cao Jiandong, Hydraulic transmission and pneumatics Technology,Peking University Press, Beijing,2006. pp.112-130

[4]Zhao Jiawen. On the functions of the pressure reducing valve, Hydraulic and pneumatic, J. (4) (2009)64-65. 